\title{
Chairmen of Symposium Sessions
}

Kenneth F. Baker, Department of Plant Pathology, University of California, Berkeley

P. W. BriAN, Department of Botany, University of Glasgow, Scotland

J. L. HARLEY, Department of Botany, University of Sheffield, England

George H. Hepting, Southeastern Forest Experiment Station, U.S. Department of Agriculture, Asheville, North Carolina
James Tammen, Department of Plant Pathology, The Pennsylvania State University, University Park

William C. SNyder, Department of Plant Pathology, University of California, Berkeley

George A. Zentmyer, Department of Plant Pathology, University of California, Riverside 